\title{
Cytoprotective effect of cytoflavinum in the treatment of thermal injuries of various severity levels
}

\author{
Alexey J. Bozhedomov ${ }^{1}$, Vitaliy V. Morrison ${ }^{1}$, Nataliya M. Shulayeva ${ }^{2}$, Victoria V. Nikitina ${ }^{1}$, Inna L. Ivanenko ${ }^{1}$ \\ ${ }^{1}$ Saratov State Medical University n.a. V.I. Razumovsky, Saratov, Russia \\ ${ }^{2}$ Saratov Burns Centre, Saratov, Russia
}

Accepted 20 October 2012.

Original Text in Russian (C) Bozhedomov A.J., Morrison V.V., Shulaeva N.M., Nikitina V.V., Ivanenko I.L., 2012, published in Saratov Journal of Medical Scientific Research 2012; 8(1): 38-42.

\begin{abstract}
The research aimed to conduct studying of cytoprotective effect of cytoflavinum in thermal traumas of various severity levels. Material and methods - 169 patients were included into the research with thermal burns and with a favorable outcome and the severity of a thermal injury from 30 to 170 points according Frank index. 28 patients received cytoflavinum in a complex therapy in a standard dosage. Results - During the cytoflavinum usage in patients with the severity of a thermal injury more than 60 points by Frank there had been fixed: the decrease of a systemic inflammatory response syndrome (SIRS), reduction of stab neutrophils content, slower decrease of erythrocytes, smaller activation of thrombopoiesis, decrease of concentration of the vascular endothelial growth factor. In the group of patients with thermal injuries less than 60 points who had been receiving cytoflavinum there had not positive effects been fixed. Conclusion - Cytoflavinum is the most effective when the severity of a thermal trauma is more than 60 points by Frank.
\end{abstract}

Keywords: burns, endothelium, cytoflavinum.

Cite as Bozhedomov AJ, Morrison VV, Shulaeva NM, Nikitina VV, Ivanenko IL. Cytoprotective effect of cytoflavinum in the treatment of thermal injuries of various severity levels. Russian Open Medical Journal 2012; 1: 0305.

Correspondence to Alexey J. Bozhedomov. Address: Department of Pathological Physiology, Saratov State Medical University n.a. V.I. Razumovsky, 112, Bolshaya Kazachiya str., Saratov, 410012, Russia. Phone: +79173114148. E-mail: alecso_84@mail.ru

\section{Introduction}

A thermal trauma is one of actual and socially significant problems of medicine. During the burn disease progression there severe hemodynamics and microvascular disorders are formed, as well as an intensification of free radicals oxidation, evident hypoxia, profuse cytokine and proinflammatory mediators ejection, dystrophic and necrobiotic processes which lead to organs and tissues disorders and multiorgan dysfunction. High risk of complications in serious burn traumas is often connected with an activity of lipid peroxidation, cytokines ejection and development of a systemic inflammatory response syndrome [14].

Medicine today has not got any effective methods to prevent the development of the systemic inflammatory response and multiorgan dysfunction in patients with critical burns. Numerous researches are aimed on the searching of ways to protect organs.

An advanced treatment of the disease is the usage of cytoflavinum, as the drug improves energy metabolism, it has antioxidant, antihypoxant properties and protect cell membranes.

The aim of our research is to study the possibility of cytoprotective effect of cytoflavinum in patients with a thermal trauma of various severity levels in dynamics of burn disease progression.

\section{Materials and methods}

169 patients (having hospital treatment) have been included into the research in Saratov Burns Centre. That was important to exclude several comorbidities: cardiovascular and respiratory system diseases, peripheral blood diseases and infectious diseases. In the study group there were mainly males aged from 16 to 70 years $(78.1 \%$ from all of the patients) (Table 1$)$. Well-known principles of an estimation of thermal traumas severity were the basis of randomization of study groups [5]. The principles included an estimation of burn surface areas, depths of burns and Frank index. The patients with a thermal injury severity from 30 to 170 points by Frank (only with a favorable outcome) were included into the study.

Table 1. Characteristics of groups of the burn patients receiving a traditional therapy and therapy with cytoflavinum

\begin{tabular}{ccccc}
\hline Group & $\begin{array}{c}\text { Frank index, } \\
\text { points }\end{array}$ & $\begin{array}{c}\text { Sex } \\
\text { (males/females) }\end{array}$ & Age, years & $\begin{array}{c}\text { Duration of } \\
\text { treatment, } \\
\text { days }\end{array}$ \\
\hline IA $(n=66)$ & $47.5 \pm 1.2$ & $48 / 18$ & $40.8 \pm 1.2$ & $37.6 \pm 2.2$ \\
IB $(n=11)$ & $49.3 \pm 3.1$ & $9 / 2$ & $34.9 \pm 4.4$ & $33.7 \pm 3.1$ \\
IIA $(n=75)$ & $93.7 \pm 2.5$ & $61 / 14$ & $35.9 \pm 1.2$ & $59.9 \pm 2.3$ \\
IIB $(n=17)$ & $102.3 \pm 7.2$ & $14 / 3$ & $31.5 \pm 2.5$ & $56.8 \pm 5.3$ \\
\hline
\end{tabular}


Physiology and Pathophysiology

Table 2. Quantity of blood corpuscle in burn disease dynamics on the background of a traditional therapy and cytoflavinum usage

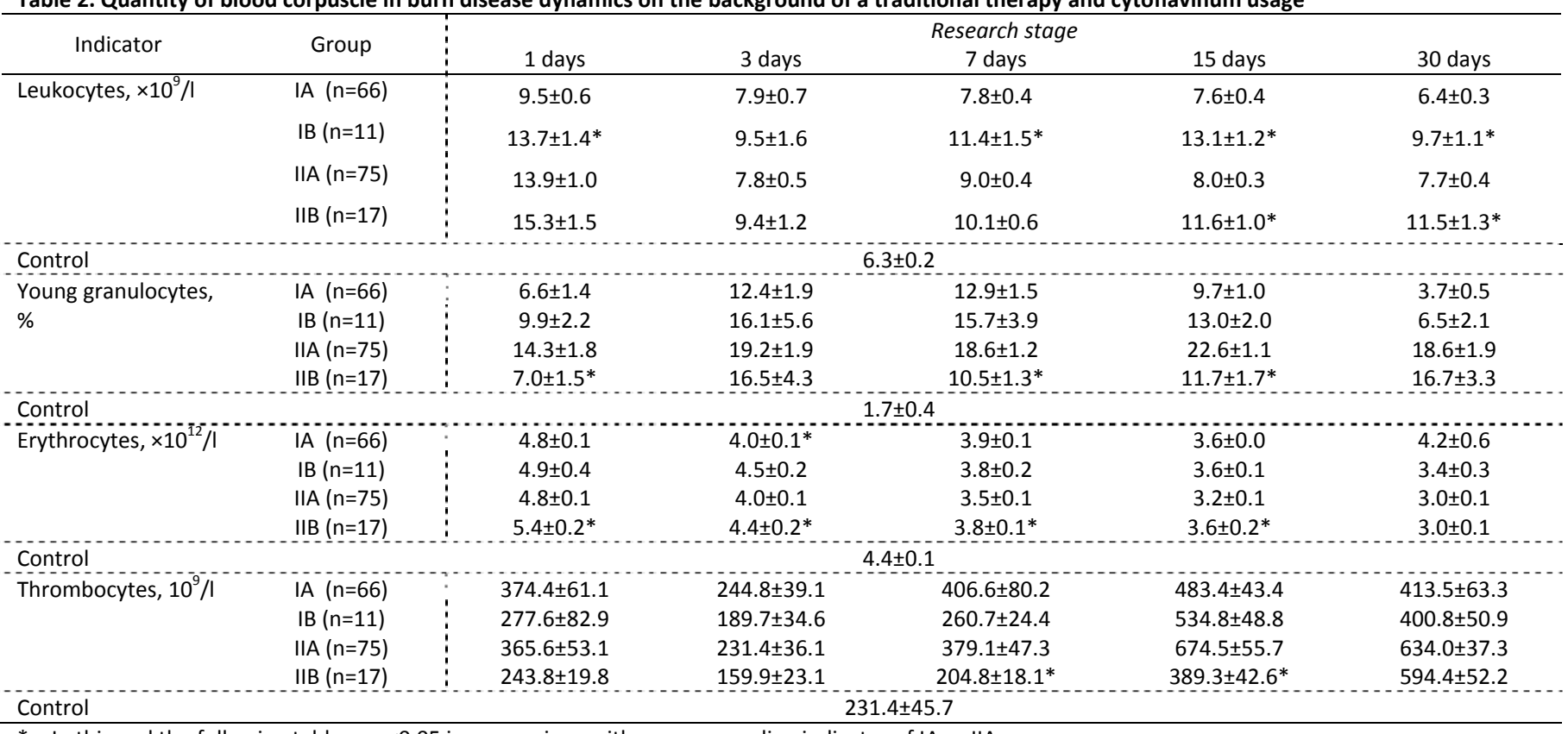

* - In this and the following tables $-\mathrm{p}<0,05$ in comparison with a corresponding indicator of IA or IIA groups.

141 patients received a standard complex therapy to block a pain syndrome, compensation of circulating blood volume, microcirculation recovery, metabolic disturbance and hemostasis correction, compensation of protein deficiency, elimination of an intensifying intoxication using of standard medications. 28 patients had been receiving cytoflavinum since the day of an admission to hospital. They had been receiving intravenous cytoflavinum course of 10-14 days 1-2 times a day at a standard dosage (combined with the therapeutic interventions).

19 healthy donors had been included into the control group.

There 4 groups have been formed to study a cytoprotective effect in different thermal injuries severity levels. Group IA patients with a trauma severity less than 60 points, they had been receiving standard therapy; IB - patients with a trauma severity less than 60 points, they had been receiving treatment using cytoflavinum; IIA - patients with a trauma severity more than 60 points, they had been receiving standard therapy; IIB - patients a trauma severity more than 60 points, they had been receiving treatment using cytoflavinum.

Erythrocytes, leukocytes, platelets in peripheral blood have been quantified in the patients. The evidence of the systemic inflammatory response syndrome (SIRS) has been detected according to two or more criteria of The Chicago Consensus Conference [6]. An activity of serumal transaminases has been studied as an integrative indicator of a biomembranes stability (assay kits by "ДДС Виакон" [DeDeEs Viakon], Moscow). А vascular endothelial growth factor (VEGF) was used to evaluate a hypoxic endothelium disorder (ELISA-test assay kits by "Bender MedSystems", Austria). In order to reveal necrotic processes in endothelium vessels the quantity of circulating endothelial cells in blood (CEC) has been determined by J. Hladovec method in N.Petrishchev's updating using phase-contrast microscopy [7].

The given researches have been done on the $1 \mathrm{st}$, 3rd, 7th, 15th, 30th days since the patients got injuries.
Statistical processing has been carried out using the package of applied statistical programs Statistica 8.0 (StatSoft, USA). Data were expressed as $\mathrm{M} \pm \mathrm{m}$, where $\mathrm{M}$ - average, $\mathrm{m}$ - error in mean. Reliability of distinctions has been defined according to Student's $\mathrm{t}$-criteria. The average $\mathrm{p}<0.05$ was a criterion of reliability of average quantities difference.

\section{Results}

In patients with severe and extra-severe thermal injuries (Frank index is over 60 points) the evidence of SIRS was considerably higher than in patients with thermal injuries of a moderate severity during all terms of treatment. There are no SIRS or it arises for a short time in thermal injuries of 60 points and less (by Frank) on a period of wound cleansing or wound infection (Figure).

In patients with a thermal injury of a moderate severity the cytoflavinum usage strengthens the evidence of the SIRS a little, which had been observed in other types of pathology as well [8]. The cytoflavinum usage in the treatment of severe and extrasevere injuries reduces evidence of the SIRS.

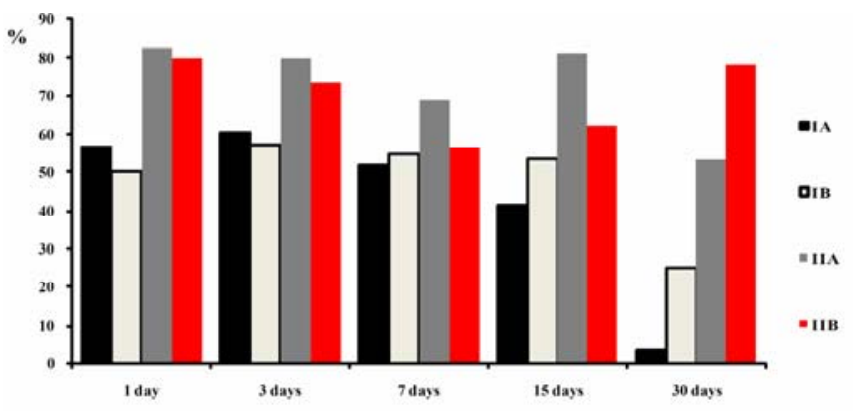

Figure. A share of patients with a quantity of criteria of SIRS >2 
Physiology and Pathophysiology

Table 3 . Activity of AST and ALT in a blood serum in burn disease on the background of a traditional therapy and cytoflavinum therapy

\begin{tabular}{|c|c|c|c|c|c|c|}
\hline \multirow[t]{2}{*}{ Indicator } & \multirow[t]{2}{*}{ Group } & \multicolumn{5}{|c|}{ Research stage } \\
\hline & & 1 days & 3 days & 7 days & 15 days & 30 days \\
\hline \multirow[t]{4}{*}{ AST, ea/I } & IA $(n=66)$ & $38.6 \pm 4.1$ & $58.3 \pm 10.5$ & $27.6 \pm 3.5$ & $60.8 \pm 13.8$ & $36.5 \pm 8.5$ \\
\hline & IB $(n=11)$ & $80.6 \pm 20.0^{*}$ & $54.0 \pm 16.2$ & $35.5 \pm 5.0$ & $32.6 \pm 6.5$ & $18.5 \pm 2.2$ \\
\hline & $\| A(n=75)$ & $75.1 \pm 16.6$ & $43.2 \pm 7.1$ & $40.6 \pm 5.0$ & $34.3 \pm 3.5$ & $39.8 \pm 6.7$ \\
\hline & IIB (n=17) & $45.4 \pm 9.5$ & $65.3 \pm 21.2$ & $49.2 \pm 10.1$ & $39.5 \pm 4.8$ & $29.1 \pm 2.0$ \\
\hline Control & \multicolumn{6}{|c|}{$17.6 \pm 2.0$} \\
\hline \multirow[t]{4}{*}{$\mathrm{ALT}, \mathrm{ea} / \mathrm{I}$} & IA $(n=66)$ & $34.8 \pm 4.6$ & $40.5 \pm 6.5$ & $34.4 \pm 3.7$ & $61.8 \pm 9.6$ & $34.2 \pm 7.9$ \\
\hline & IB $(n=11)$ & $60.1 \pm 15.1^{*}$ & $34.1 \pm 7.0$ & $40.9 \pm 10.4$ & $37.4 \pm 9.9$ & $18.9 \pm 3.1$ \\
\hline & $\| A(n=75)$ & $44.183 \pm 6.1$ & $31.0 \pm 3.6$ & $41.3 \pm 8.5$ & $41.7 \pm 5.0$ & $42.1 \pm 7.0$ \\
\hline & IIB $(n=17)$ & $30.27 \pm 6.3 .8$ & $37.0 \pm 2.4$ & $65.8 \pm 14.1$ & $74.3 \pm 14.2^{*}$ & $52.7 \pm 10.3$ \\
\hline Control & \multicolumn{6}{|c|}{$17.1 \pm 1.8$} \\
\hline
\end{tabular}

Table 4. Concentration of VEGF and CEC content in a blood plasma in burn disease dynamics on the background of a traditional therapy and cytoflavinum usage

\begin{tabular}{|c|c|c|c|c|c|c|}
\hline \multirow[t]{2}{*}{ Indicator } & \multirow[t]{2}{*}{ Group } & \multicolumn{5}{|c|}{ Research stage } \\
\hline & & 1 days & 3 days & 7 days & 15 days & 30 days \\
\hline \multirow[t]{4}{*}{ VEGF, $\mathrm{pg} / \mathrm{ml}$} & IA $(n=66)$ & $287.7 \pm 78.5$ & $281.2 \pm 101.6$ & $516.6 \pm 240.8$ & $525.9 \pm 134.0$ & $288.4 \pm 51.9$ \\
\hline & IB $(n=11)$ & $765.8 \pm 383.6$ & $893.7 \pm 555.4$ & $568.5 \pm 271.2$ & $369.0 \pm 115.5$ & $324.3 \pm 203.0$ \\
\hline & IIA $(n=75)$ & $603.3 \pm 238.6$ & $766.0 \pm 284.3$ & $1595.7 \pm 569.4$ & $812.1 \pm 222.4$ & $845.1 \pm 156.8$ \\
\hline & IIB $(n=17)$ & $295.1 \pm 109.6$ & $212.2 \pm 145.0$ & $914.9 \pm 516.1$ & $815.9 \pm 232.6$ & $574.2 \pm 361.2$ \\
\hline Control & \multicolumn{6}{|c|}{$28.7 \pm 3.6$} \\
\hline \multirow[t]{4}{*}{ CEC, $\times 10^{4} / I$} & IA $(n=66)$ & $3.9 \pm 1.2$ & $4.6 \pm 1.5$ & $6.0 \pm 1.9$ & $4.2 \pm 0.7$ & $2.4 \pm 0.5$ \\
\hline & IB $(n=11)$ & $3.5 \pm 1.0$ & $5.5 \pm 1.5$ & $2.8 \pm 0.5$ & $4.8 \pm 0.9$ & $4.3 \pm 0.9$ \\
\hline & IIA $(n=75)$ & $1.8 \pm 0.9$ & $5.7 \pm 1.5$ & $6.0 \pm 2.2$ & $8.7 \pm 1.6$ & $4.6 \pm 0.8$ \\
\hline & IIB $(n=17)$ & $4.0 \pm 1.4$ & $4.0 \pm 1.0$ & $9.7 \pm 2.8$ & $8.6 \pm 1.3$ & $4.5 \pm 1.5$ \\
\hline Control & \multicolumn{6}{|c|}{$2.8 \pm 0.5$} \\
\hline
\end{tabular}

Using of cytoflavinum promotes an increase of more evident leukocytosis in thermal injury of a moderate severity as well as in severe thermal injury comparing with patients which had not got cytoflavinum. However in patients with Frank index of more than 60 points, in comparison with group of patients receiving a standard therapy, there is a decrease of a percentage of young neutrophils forms (Table 2). This demonstrates indirectly the longer functioning of leukocytes and smaller activation of a leukocytic pool in the patients receiving cytoflavinum.

An addition of cytoflavinum into the treatment has shown a positive cytoprotective effect in relation to peripheral blood erythrocytes. Thus, in patients with a severe thermal injury the more evident effect of a drug using had been noticed (Table 2).

A total thrombocytes count indirectly reflects activation of a blood coagulation system. Necrectomies which had been performed in 7-13 days after getting injured and accompanied by blood loss, activated thrombocytopoesis (Table 2) in all groups of patients.

In the patients receiving a complex of treatment with cytoflavinum, the lower content of peripheral blood thrombocytes has been fixed than in the patients receiving a standard therapy. Thus, there have not clinical and laboratory indicators of coagulation failure been revealed. The amount of thrombocytes in the group of patients receiving cytoflavinum was within normal limits, which indicates smaller thrombocytopoesis intensity in this group of patients and more stability of thrombocytes as on the background of toxic factors, as well as activators of coagulation in their burn wounds blood flow. By the 30th day this indicator had become equal in patients from groups with identical injury severity (Table 2)

An activity of serumal transaminases, which is one of indicators of biological membranes stability of hepatocytes and myocytes, keeps being at a high level during both of traditional complex and cytoflavinum therapies (Table 3).

Further there have been studied circulating endothelial cells (CEC) in a blood serum. This test objectively indicates vascular endothelium disruption [7]. During the traditional therapy CEC have been increased in 3 days after getting injured and keeps being increased during all the period of the study (Table 4). These disorders are more evident in severe thermal injuries. It should be noted, that inclusion of cytoflavinum into a complex therapy did not really influence on the endotheliocytes content in CEC.

VEGF shows a regenerative activity of endothelium as well as a severity of hypoxia [9]. This indicator was very variable in patients from all of the groups. In a burn injury an intensive increase of the VEGF level has been fixed during the standard therapy (Table 4). The VEGF concentration in severe and extra-severe injuries increases at a burn shock stage and has been keeping high level during all the supervision period. Inclusion cytoflavinum into a complex therapy in patients with a severe thermal injury promotes the decrease of VEGF concentration only at a stage of a burn shock and after it.

\section{Discussion}

Cytoflavinum is used in many areas of medicine: it is a welltried detoxicator and is also used in hypoxia, a drug with antihypoxant and antioxidant properties, and protects cell 
membranes. The main purpose of cytoflavinum is an activation of a glucose breakdown in a tricarboxylic acid cycle, and as a result, intensifying of cell energy metabolism [10-12].

A severe toxic cells disease of a whole organism is fixed in a thermal injury, which is caused by: a severe hypoxia progression, regional blood flow and microcirculation disorders, metabolic oxidative stress development leading to an intensifying of active oxygen forms generation, progressing activation of lipid peroxidation processes and suppression of antioxidant protection mechanisms. Using of cytoflavinum in a complex therapy of a burn shock provides positive dynamics of metabolic shifts, preventing an excessive intensification of lipid peroxidation processes [3, 12].

The given research has showed that an intensive complex therapy with the usage of the metabolic compensator - the cytoflavinum drug - is simultaneously capable to slow down anemia development, to increase a leukocytes quantity and decrease a share of young neutrophils, to limit thrombocytes quantity increase. Lower indicators of VEGF show the decrease of endothelium hypoxic disease. An activation of the SIRS on later periods of supervision (15, 30 days after trauma reception), probably, can be explained by an increased activation of granulocytes, which are able function effectively for a long time, and biologically active substances produced by granulocytes are the stimulators of a systemic inflammatory reaction. Using of cytoflavinum, probably, promotes development of co-called "the second strike": the granulocytes activated by an injury react much more stronger [13].

\section{Conclusion}

Using of cytoflavinum in a complex therapy is effective in severe and extra-severe thermal injuries of 60 and more points by Frank. An efficiency of a drug in thermal injury of a moderate severity is doubtful.

\section{Conflict of interest}

The study is executed within the limits of program scientifically research of Saratov State Medical University (Saratov, Russia), the number of state registration: 01200959762 .

\section{Reference}

1. Abdel-Hafez NM, Saleh Hassan Y, El-Metwally TH. A study on biomarkers, cytokines, and growth factors in children with burn injuries. Ann Burns Fire Disasters 2007; 20(2): 89-100 (PMID: 21991076) (PMCID: PMC3188064).

2. Shulayeva NM, Kuspits YeV, Shchukovsky VV, Fisun AM. Obosnovaniye primeneniya antioksidantnoi terapii pri lechenii sindroma endogennoi intoksikatsii u bolnykh s tyazholoi termicheskoi travmoi [Reasons of the antioxidant therapy in endointoxication syndrome in the treatment of patients with a severe thermal injury]. Skoraya meditsinskaya pomoshch 2010; (3): 76-81 [Article in Russian].

3. Chesnokova NP, Polutova NV, Ostrovsky NV, Nevvazhai TA. Patogenez ozhogovogo shoka i termicheskikh porazhenii razlichnoi stepeni tyazhesti [Pathogenesis of a burn shock and thermal injuries of different severity levels]. Akademiya yestestvoznaniya, Moscow, Russia, 2009: 237-279 [Text in Russian].

4. Samoilenko GYe. Sindrom poliorgannoi nedostatochnosti v khirurgii ozhogov u detei [Multiple-organ-failure syndrome in children thermal injuries in surgical practice]. Trauma 2000; 1(1): 46-52 [Article in Russian].

Url: http://www.dniito.dn.ua/pages/journals/trauma/2000_1.pdf
5. Paramonov BA, Porembsky YaO, Yablonsky VG. Ozhogi: rukovodstvo dlya vrachei [Thermal injuries: doctors guide]. SpecLit Publ., St. Petersburg, Russia, 2000 [Text in Russian].

6. Bone RC, Balk RA, Cerra FB, et al. American College of Chest Physicians / Society of Critical Care Medicine Consensus Conference: Definitions for sepsis and organ failure and guidelines for the use of innovative therapies in sepsis. Crit Care Med 1992; 20(6): 864-874 (PMID: 1597042).

7. Petrishchev NN, Berkovich OA, Vlasov TD, Volkova EV, Zueva EE, Mozgovaia EV. Diagnostic value of evaluation of desquamated endothelial cells in blood. Klin Lab Diagn 2001; (1): 50-52 [Article in Russian] (PMID: 11233277).

8. Zhernova EV, Vyalova NM, Ivanova SA, Bohan NA. Parameters of programmed death of lymphocytes and neutrophils in persons with alcohol intoxication in dynamic of therapy preparation with antioxidant properties. Tomsk State Pedagogical University Bulletin 2009; (3): 59-62 [Article in Russian]. Url: http://vestnik.tspu.ru/index.php?option=com_content\&task=view\&id $=1427 \&$ Itemid $=276$

9. Ferrata N, Gerber HP, Le Couter J. The biology VEGF and its receptors. Nat Med 2003; 9(6): 669-676 (PMID: 12778165) (doi:10.1038/nm0603669).

10. Afanasyev VV. Tsitoflavin v intensivnoi terapii [Cytoflavinum usage in emergency treatment]. St. Petersburg, Moskow, 2005 [Text in Russian].

11. Markevich PS, Danilenko SU, Yankin AV, Plekhanov AN. Tochki prilozheniya tsitoflavina na vnutrikletochnyye biokhimicheskiye protsessy [Cytoflavinum spots in intracellular biochemical processes]. Bulletin of the East-Siberian Scientific Center of Siberian Department of Russian Academy of Medical Sciences 2011; (1): 232-246.

12. Polutova NV, Ostrovskiy NV, Romantsov MG, Chesnokova NP. Polozhitelnoye vliyaniye tsitoflavina na sdvigi metabolicheskogo statusa pri ozhogovom shoke [Positive effect of cytoflavinum in metabolic status shifts in a burn shock]. Eksperimentalnaya $i$ klinicheskaya farmakologiya 2011; 74(7): 33-37.

13. Mikhalchik YeV. Pokazateli okislitelnogo stressa pri ozhogovoi travme [Indicarirs of an oxidative stress in thermal injury] (D.Sc. dissertation work). Moscow, 2006.

Authors:

Alexey J. Bozhedomov - MD, Post-graduate, Department of Pathological Physiology, Saratov State Medical University n.a. V.I. Razumovsky, Saratov, Russia;

Vitaliy V. Morrison - MD, D.Sc., Professor, Head of Department of Pathological Physiology, Saratov State Medical University n.a. V.I. Razumovsky, Saratov, Russia;

Nataliya M. Shulayeva - MD, Head of Anesthesiology and Resuscitation Department, Saratov Burn Centre, Saratov, Russia;

Victoria V. Nikitina - Senior Researcher, Central Scientific Research Laboratory, Saratov State Medical University n.a. V.I.Razumovsky;

Inna L. Ivanenko - Senior Researcher, Central Scientific Research Laboratory, Saratov State Medical University n.a. V.I. Razumovsky, Saratov, Russia. 